\title{
Tooth bleaching using a diode laser
}

Surface and pulp chamber temperature rises during tooth bleaching using a diode laser: a study in vitro M. Sulieman, J. S. Rees and M. Addy Br Dent J 2006; 200: 631-634

\section{Objective}

To measure the surface and pulp chamber temperature increases in vitro on upper and lower anterior teeth during a tooth whitening procedure using a diode laser.

Method

A thermocouple was used to measure the temperature increase on the surface of an extracted upper central incisor tooth. Pulp chamber temperature readings were made on upper and lower central incisors, lateral incisors and canines. A diode laser recommended for tooth bleaching was tested at three different power settings ( $1 \mathrm{~W}, 2 \mathrm{~W}, 3 \mathrm{~W}$ ). Temperature measurements were made with and without the bleaching agent present on the labial tooth surface.

Results

The increase in surface temperature readings ranged from $37^{\circ} \mathrm{C}(1 \mathrm{~W})$ to $86.3^{\circ} \mathrm{C}(3 \mathrm{~W})$ with no bleaching gel present. Pulp chamber temperature increases ranged from $4.3^{\circ} \mathrm{C}(1 \mathrm{~W})$ to $16^{\circ} \mathrm{C}(3 \mathrm{~W})$. The presence of the bleaching gel reduced temperature increases seen at the tooth surface and within the pulp.

\section{Conclusions}

The increase in the pulp chamber temperature with the laser used at $1-2 \mathrm{~W}$ was below the critical temperature increase of $5.5^{\circ} \mathrm{C}$ thought to produce irreversible pulpal damage. However, a power setting of $3 \mathrm{~W}$ produced a pulp chamber temperature increase above this threshold $\left(16^{\circ} \mathrm{C}\right)$ and caution is advised when using this setting.

\section{IN BRIEF}

- Bleaching gels activated by Diode lasers in Power Bleaching act as effective insulators, helping prevent large increases in temperatures within the pulp chamber.

- Teeth should never be directly irradiated with laser energy without the presence of the bleaching gel.

- Temperature rises within the pulp chamber reduce to baseline levels very quickly after removal of laser irradiation.

- Diode lasers used to activate bleaching gels are not considered dangerous to the vitality of dental pulps using power settings of up to $2 \mathrm{~W}$.

\section{COMMENT}

This article is particularly interesting because it may help to remind us that lasers and their use in dentistry are by no means history. Many will recall the heady days of the early 1990s when it was thought by some that the laser would rapidly replace the dental drill for cutting dental hard tissues. The truth is that our understanding of laser/tissue interactions was then scanty, especially in dentistry, and the lasers then being employed were generally inappropriate for the uses to which they were being put. A number of dentists spent a lot of money on machines which were ineffective, and as a result mainstream dentistry has rather neglected the laser since.

In the subsequent years much very useful basic work has being going on. In medical fields, of course, lasers are now accepted technology, especially in opthalmics and surgery. In clinical dentistry, we now have lasers that will cut hard tissues without serious side effects but they are still a little slow compared to the handpiece. In other dental areas there has been steady growth in knowledge and application. Endodontics has been a particularly widely investigated area.

One of the perceived dangers of lasers has always been heat generation. This needs to be put in context, since it is well known that a poorly cooled or operated handpiece can generate very large temperature rises. In this article the authors look at the temperature rises at the surface and in the pulp chamber when a diode laser is used as part of a tooth-whitening procedure. Increasing the laser power setting from just $2 \mathrm{~W}$ to $3 \mathrm{~W}$ was enough to exceed the critical rise of $5.5^{\circ} \mathrm{C}$ suggested as causing irreversible pulp damage.

It shows how fine a pathway we tread and the need to be careful with heat generation in all circumstances. It also suggests the need to look again at the fundamental work of Zach and Cohen which was carried out way back in 1965 and which has been quoted ever since in relation to thermal damage of teeth. They used a soldering iron to heat their samples and carried out their work before the era of infrared thermography or computer modelling. Looking again at thermal damage of teeth might well moderate some concerns about lasers but possibly might make us question again the adequacy of water cooling for conventional cutting tools used in dentistry.

C. E. Mercer, Centre for Adult Oral Health, Queen Mary's School of Medicine and Dentistry

DOI: $10.1038 /$ sj.bdj.4813647 